\title{
O TRATAMENTO DA POLISSEMIA E DA HOMONÍMIA NOS LEARNER'S DICTIONARIES: SUBSÍDIOS DA SEMÂNTICA COGNITIVA PARA A DISPOSIÇÃO DAS ACEPÇÕES
}

\author{
Ana Flávia Souto de OLIVEIRA* \\ Félix Bugueño MIRANDA** \\ Maity SIQUEIRA***
}

- RESUMO: No âmbito lexicográfico, diversas são as questões impostas pela consideração dos fenômenos da polissemia e da homonímia. Neste trabalho, abordamos dois problemas centrais: (i) a solução adotada para a estruturação dos verbetes (solução polissêmica ou solução homonímica) e (ii) os critérios empregados para a organização das acepções dentro dos verbetes. Para isso, apresentamos análises de itens lexicais presentes nos quatro principais learner's dictionaries - CALD (2008), COBUILD (2006), LDCE (2009) e OALD (2005)ํ․ Nelas constatamos que não há homogeneidade nas soluções empregadas, tanto entre as obras quanto dentro da mesma obra para o tratamento do mesmo fenômeno, e que o critério empregado pelos dicionários para a organização das acepções, a frequência, é problemático, tanto por questões anteriores a sua aplicação quanto por problemas exclusivos a esse critério. Dessa forma, buscamos na concepção de polissemia da Semântica Cognitiva um modelo de descrição que auxiliasse na disposição das acepções nos verbetes de learner's dictionaries. Ao final, apresentamos nossa sugestão de verbete para o item lexical band. Concluímos com uma avaliação das questões que nosso modelo consegue tratar de forma mais efetiva e trazemos ainda problemas para os quais continuamos sem solução.

- PALAVRAS-CHAVE: Lexicografia. Polissemia. Semântica cognitiva. Learner's dictionaries. Ordenação das acepções. Solução polissêmica. Solução homonímica.

\section{Introdução}

A distinção entre os fenômenos da polissemia e da homonímia vem sendo discutida desde os primórdios da semântica lexical, com a tradição

* Bolsista CAPES. Doutoranda em Letras. UFRGS - Universidade Federal do Rio Grande do Sul. Instituto de Letras - Pós-Graduação em Letras. Porto Alegre - RS - Brasil. 91540-000 - anaflavia10@gmail.com

** UFRGS - Universidade Federal do Rio Grande do Sul. Instituto de Letras - Departamento de Línguas Modernas. Porto Alegre - RS - Brasil. 91540-000 - felixv@uol.com.br

*** UFRGS - Universidade Federal do Rio Grande do Sul. Instituto de Letras - Departamento de Linguística, Filologia e Teoria Literária. Porto Alegre - RS - Brasil. 91540-000 - maitysiqueira@hotmail.com

1 Seguindo a tendência da metalexicografia europeia, os dicionários serão representados pelo uso de siglas, seguido do ano de publicação. 
histórico-filológica, e até os dias atuais persiste como questão fundamental nos estudos lexicais. Grosso modo, os casos de polissemia ocorrem quando "[...] dois ou mais significados relacionados estão associados a uma mesma forma linguística." (TAYLOR, 2003a, p.103), como o item lexical do inglês head, com os significados "parte superior do corpo" e "líder", que, mesmo sendo significados claramente distintos, mantêm uma relação metonímica. Já a homonímia ocorre quando "[...] uma única forma fonológica possui significados não relacionados." (RIEMER, 2010, p.161). Por exemplo, os significados "caso" e "bolsa" do inglês case advêm de origens etimológicas distintas e não apresentam qualquer relação semântica evidente, sendo, por isso, considerados dois itens lexicais distintos homônimos.

Contudo, a diferenciação entre esses dois fenômenos, muitas vezes, não é clara, pois diferentes critérios podem gerar resultados distintos. Uma visão de viés histórico, por exemplo, afirma que casos de polissemia advêm da mesma origem etimológica, enquanto itens homônimos não possuem relação quanto a esse aspecto. O critério de consciência coletiva, por sua vez, considera a percepção dos falantes quanto aos significados possuírem ou não relação entre si. A esse respeito, Crystal afirma que sempre há um conflito entre o critério histórico e o de intuição ao se diferenciar casos de polissemia e de homonímia (CRYSTAL, 1997, s.v. polysemy and homonymy).

Ao passarmos da esfera lexicológica ao âmbito lexicográfico, as considerações a respeito dos fenômenos da polissemia e da homonímia podem não ser diretamente aplicáveis, pois toda a organização dos dicionários é condicionada por fatores como o perfil de usuário e o tipo de obra. Desse modo, quanto a esses fenômenos, o primeiro problema que se instaura diz respeito à decisão sobre como tratar cada um desses casos nas obras, o que denominamos a adoção de uma solução polissêmica ou solução homonímica.

A seguir, surgem questões lexicográficas diretamente relacionadas à estrutura semasiológica dos itens lexicais, como (i) a delimitação do número de significados de um item lexical e o conteúdo semântico de cada um deles; (ii) a descrição do conteúdo desses significados, relacionada à problemática da definição; e (iii) a opção por uma forma de organizar esses significados, ou seja, de que modo agrupálos e ordená-los (RAVIN; LEACOCK, 2000). Neste trabalho, focou-se no terceiro problema, dando ênfase à análise da disposição das acepções em dicionários monolíngues de inglês para aprendizes de L2: os learner's dictionaries ${ }^{2}$.

[dicionários de aprendizes] Pelo fato de o termo learner's dictionary já ser consagrado na Metalexicografia para designar especificamente obras monolíngues para falantes não nativos, preferimos nos referir a esse genótipo lexicográfico mantendo a terminologia do inglês, em vez de utilizar sua tradução. Além disso, no português, o termo dicionário pedagógico ainda abarca diversos tipos de obras, desde os dicionários para aprendizes de língua materna até obras bilíngues voltadas ao público aprendiz. 
Para isso, realizamos o seguinte percurso: primeiramente, apresentamos os critérios que estabelecemos, de modo a avaliar a disposição das acepções nos verbetes dos learner's dictionaries, e as análises decorrentes da avaliação de quatro dicionários desse tipo. Consideramos como parâmetros, por um lado, a solução adotada pelas obras para a estruturação dos verbetes (homonímica ou polissêmica) e, por outro, o critério empregado para a ordenação das acepções e seu agrupamento.

Na segunda parte do trabalho, apresentamos, num primeiro momento, a concepção de polissemia da Semântica Cognitiva e, posteriormente, discutimos sua aplicação para a estruturação dos verbetes dos dicionários, exemplificando com o verbete que redigimos para o item lexical band. Finalmente, concluímos o trabalho discutindo os resultados obtidos e considerando pontos que ainda necessitam de maior desenvolvimento.

Para as nossas análises, utilizamos as últimas edições dos quatro principais learner's dictionaries disponíveis: CALD (2008), COBUILD (2006), LDCE (2009) e OALD (2005). ${ }^{3}$

\section{Critérios de avaliação da organização do verbete}

Em Oliveira (2010a, 2010b), postulamos que a organização das acepções nos dicionários deveria ser analisada a partir da consideração de dois critérios: (i) a solução adotada para a apresentação do verbete (solução homonímica ou solução polissêmica) e (ii) o critério empregado para a ordenação e o agrupamento das acepções. Abaixo, apresentamos cada um desses conceitos e as análises relativas a cada um deles realizadas nos learner's dictionaries.

\section{Solução homonímica e polissêmica}

Quanto à solução adotada, primeiramente é necessário salientar que a polissemia e a homonímia como questões lexicológicas são fatos distintos do tratamento que esses fenômenos recebem na Lexicografia. Isso porque os dicionários exigem que a representação desses fenômenos seja adaptada de acordo com o tipo e a função da obra e o perfil de usuário (OLIVEIRA, 2010c).

Para apresentar tal distinção, consideramos o item lexical bank. Segundo OED (1933, s.v. bank sb. ${ }^{1,3}$ ), os significados "margem" e "instituição financeira" de bank se referem a dois itens lexicais com etimologias distintas, assim,

Essas eram as versões mais recentes disponíveis quando realizamos a pesquisa. Atualmente, o OALD possui outra edição (OALD, 2010). 
entendido como um caso de homonímia. O primeiro, do norueguês antigo *banke, *banki, e o segundo, do francês banque e do italiano banca. Porém, mesmo que lexicologicamente esse seja considerado um caso de homonímia, em uma obra lexicográfica, pode-se optar por adaptar esse dado lexicológico a uma apresentação que seja apropriada às necessidades do seu usuário ou que leve em consideração o tipo de dicionário.

Abaixo, apresentamos dois verbetes de bank retirados de COBUILD (2006):

\section{bank $^{1}$}

1 A bank is an institution where people or businesses can keep their money [...]. (COBUILD, 2006, s.v. bank).

\section{bank $^{2}$}

1 The banks of a river, canal, or lake are the raised areas of ground along its edge [...]. (COBUILD, 2006, s.v. bank).

O dicionário COBUILD (2006) traz verbetes distintos para as acepções de bank, o primeiro compreende o significado "instituição financeira" e o segundo, "margem". Dessa forma, essa obra opta pelo emprego de uma solução homonímica ao apresentar as acepções de bank. Consideremos, agora, o verbete de OALD (2005) para o mesmo item lexical:

\section{bank $[\ldots]$}

FOR MONEY 1 an organization that provides various financial services, for example keeping or lending money [...]

OF RIVER/CANAL 4 the side of a river, canal, etc. and the land near it [...]. (OALD, 2005, s.v. bank).

OALD (2005) opta por integrar as duas acepções, "instituição financeira" e "margem", em um único verbete, adotando, assim, uma solução polissêmica.

Desse modo, classificamos de solução homonímica casos nos quais o dicionário separa os itens lexicais em verbetes distintos seguindo um critério etimológico (um verbete para cada item com mesma origem etimológica), morfológico (um verbete para cada classe gramatical que o item apresenta) ou semântico (um verbete para cada bloco de significados que compartilhem conteúdo semântico). Os verbetes de bank apresentados por COBUILD (2006) são um caso de solução homonímica por critério etimológico ou semântico. ${ }^{4}$

A solução polissêmica, por sua vez, ocorre quando a obra apresenta as informações relativas à forma linguística em um único verbete, desconsiderando

\footnotetext{
4 Aqui, é importante salientar que mesmo que às vezes o resultado da estruturação a partir desses dois critérios coincida, eles não são iguais. Porém, como alguns dicionários não explicitam o critério empregado para tal organização, não é possível asseverar qual dos critérios é utilizado.
} 
as relações etimológicas, morfológicas ou semânticas mantidas entre os itens lexicais. No caso de bank no OALD (2005), mesmo que haja uma homonímia, o dicionário opta por apresentar as duas acepções no mesmo verbete.

A partir destes postulados, buscamos avaliar a forma como cada um dos quatro dicionários analisados - CALD (2008), COBUILD (2006), LDCE (2009) e OALD (2005) - representa os fenômenos da homonímia e da polissemia, ou seja, qual tipo de solução os dicionários adotam para sua estruturação, homonímica ou polissêmica. Analisamos os verbetes dos itens lexicais homonímicos homógrafos homófonos ${ }^{5}$ bank, case e lie e os verbetes dos itens accident, band, branch, close, fresh e reason. ${ }^{6} \mathrm{O}$ foco das nossas análises se manteve, principalmente, nas implicações que a etimologia e as classes gramaticais apresentadas pelos itens podem trazer para a estruturação dos verbetes. ${ }^{7}$

Igualmente, buscamos, nas obras, subsídios que nos auxiliassem a definir se havia critérios explícitos estabelecidos para essa organização. Assim, avaliamos quais informações eram apresentadas no front matter ${ }^{8}$ de cada dicionário. Nesse viés, CALD (2008, p.X) afirma que apresenta as diferentes classes gramaticais de um item lexical dentro do mesmo verbete, porém, separadas em blocos distintos. Para tanto, o dicionário fornece como exemplo o verbete de heap ["pilha" (s.), "empilhar" (v.)], separado em dois blocos relativos às diferentes classes gramaticais, mas inseridos em um verbete único. Contudo, o dicionário não explicita o modo como a homonímia e a polissemia são tratadas. COBUILD (2006, p.IX) afirma que apresenta diferentes entradas para itens para os quais haja "clear sense splits" [divisões claras de significado], e traz, como exemplo, três verbetes de still ["ainda" (adv.), "parado" (adj.), "destilador" (s.)], porém, não especifica em quais casos essa divisão é empregada, nem se existe diferença no tratamento de itens homonímicos e polissêmicos. ${ }^{9} \mathrm{LDCE}$ (2009, p.X) separa itens lexicais com diferentes classes gramaticais em verbetes distintos, porém

5 Não discutimos casos de homógrafos não homófonos, pois consideramos que eles devem sempre receber um

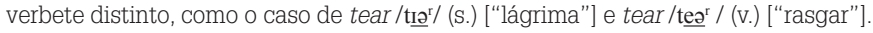

6 Todos os itens foram escolhidos aleatoriamente para as análises. O único critério que empregamos ao escolher os verbetes foi a multiplicidade de significados, tanto nos casos de polissemia quanto nos de homonímia.

7 Na língua inglesa, a importância de considerar as classes gramaticais apresentadas pelos itens lexicais é fundamental na estruturação do dicionário. Isso porque o inglês tem como característica morfológica destacada a existência de formas idênticas para diferentes classes gramaticais. Em um dicionário para aprendizes, essa característica é fundamental para a estruturação do verbete.

8 O front matter é um dos possíveis componentes do outside matter dos dicionários, junto com o middle matter e o back matter. Segundo Hausmann e Wiegand (1989), o front matter corresponde às partes funcionais que precedem a nominata, como guia de uso e quadro de abreviaturas.

9 Pelo fato de a distinção entre homonímia e polissemia nem sempre ser clara, considerar diferenças de significado como critério de separação de verbetes não garante que a polissemia e a homonímia sejam evidenciadas. Além disso, considerar como critério as "divisões claras de significado" torna necessário que sejam feitas afirmações mais aprofundadas a respeito da metodologia empregada para tal. 
também não faz referência à diferenciação entre homonímia e polissemia. Como exemplo, a obra cita os verbetes de beard, um para cada classe gramatical ["barba" (s.) e "desafiar" (v.)]. OALD (2005, p.IX) afirma que itens lexicais que apresentam diferentes classes gramaticais são estruturados em um verbete único, mas organizados em blocos distintos. Para esses casos, como exemplo, a obra traz o verbete de blindfold ["venda" (s.), "vendar" (v.) e "vendado" (adj., adv.)]. Já os casos de homônimos não homófonos recebem entradas distintas, como o exemplo fornecido gill [/gil/, "brânquia" (s.), e /ḑ̧Il/, "medida equivalente a um quarto de pints" (s.)]. Nenhum comentário é feito a respeito da distinção entre polissemia e homonímia.

As informações trazidas nos dicionários são sumarizadas no quadro abaixo:

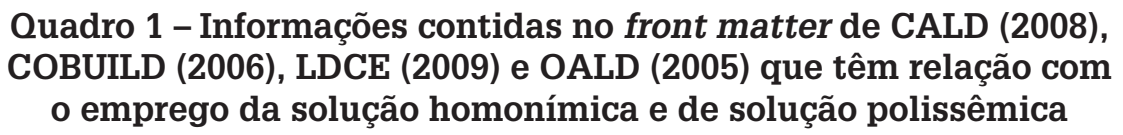

\begin{tabular}{|l|l|l|l|l|}
\hline & CALD (2008) & COBUILD (2006) & LDCE (2009) & OALD (2005) \\
\hline $\begin{array}{l}\text { Diferenciação } \\
\text { entre homonímia } \\
\text { e polissemia }\end{array}$ & não explicitada & não explicitada & não explicitada & $\begin{array}{l}\text { não explicitada } \\
\text { homônimos não } \\
\text { homófonos em } \\
\text { verbetes distintos }\end{array}$ \\
\hline $\begin{array}{l}\text { Classes } \\
\text { gramaticais }\end{array}$ & $\begin{array}{l}\text { verbete único, } \\
\text { em blocos } \\
\text { diferentes } \\
\text { por classe } \\
\text { gramatical }\end{array}$ & não explicitada & $\begin{array}{l}\text { verbetes distintos } \\
\text { para cada classe } \\
\text { gramatical }\end{array}$ & $\begin{array}{l}\text { verbete único, em } \\
\text { blocos diferentes } \\
\text { por classe } \\
\text { gramatical }\end{array}$ \\
\hline $\begin{array}{l}\text { Outros } \\
\text { comentários }\end{array}$ & - & $\begin{array}{l}\text { diferentes } \\
\text { verbetes para } \\
\text { "divisões claras de } \\
\text { significado" }\end{array}$ & - & \\
\hline
\end{tabular}

Fonte: Oliveira (2010a, p.93).

A partir desses dados contidos nas obras, buscamos avaliar (i) qual solução cada uma das obras adota para cada tipo de fenômeno, (ii) se o mesmo dicionário mantém um padrão no tratamento do mesmo tipo de fenômeno para a estruturação dos verbetes e (iii) se há homogeneidade no emprego das soluções entre as obras para casos semelhantes.

Nos dicionários, encontramos quatro configurações dessas soluções. A primeira chamamos de solução polissêmica total, na qual as acepções são todas 
apresentadas no mesmo verbete. Como exemplo, temos o verbete de reason de COBUILD (2006), que agrupa as acepções para diferentes classes gramaticais no mesmo verbete.

reason $n 1$ The reason for something is a fact or situation which explains why it happens or what causes it to happen [...] $v \mathbf{4}$ If you reason that something is true, you decide that it is true after thinking carefully about all the facts [...]. (COBUILD, 2006, s.v. reason).

O segundo tipo, também do tipo polissêmico, chamamos de solução polissêmica parcial, pois as acepções são apresentadas dentro do mesmo verbete, mas divididas em blocos a partir das diferentes classes gramaticais que o item apresenta. Isso ocorre no verbete de bank de OALD (2006) apresentado abaixo:

\section{bank $[\ldots]$ \\ - noun}

FOR MONEY 1 an organization that provides various financial services, for example keeping or lending money $[\ldots]$

\section{- verb}

MONEY 1 [VN] to put money into a bank account [...]. (OALD, 2006, S.v. bank).

O dicionário traz as diferentes acepções em um verbete, mas separa as acepções em blocos relativos ao substantivo e ao verbo bank. O terceiro tipo de solução encontrado foi chamado de solução homonímica por critério morfológico, no qual as acepções de cada classe gramatical recebem um verbete distinto. Um exemplo dessa configuração é apresentado abaixo, extraído do LDCE (2009).

\section{bank $^{1}[\ldots] n$}

1 PLACE FOR MONEY a) a business that keeps or lends money and provides other financial services [...]. (LDCE, 2009, s.v. bank).

\section{bank $^{2} V$}

1 MONEY a) [T] to put or keep money in a bank [...]. (LDCE, 2009, s.V. bank).

Nesse caso, o LDCE (2009) opta por separar as acepções do item lexical bank em verbetes que reúnam apenas as acepções referentes à mesma classe gramatical, de forma que a obra apresenta um verbete para as acepções de bank substantivo e um para bank verbo. Finalmente, o quarto tipo de solução que encontramos diz respeito ao emprego de uma solução homonímica por critério semântico ou etimológico ${ }^{10}$, no qual as acepções são apresentadas de acordo

10 Pela dificuldade citada acima para distinguir os dois casos, julgamos pertinente manter os dois critérios, semântico e etimológico, incluídos no mesmo tipo. 
com suas relações etimológicas ou semânticas. Abaixo, temos um verbete de COBUILD (2006) que exemplifica esse tipo de solução:

$\mathbf{b a n k}^{\mathbf{1}}[\ldots] \mathbf{1} \mathbf{n}$ A bank is an institution where people or businesses can keep their money. [...] v 3 If you bank money, you pay it into a bank [...]. (COBUILD, 2006, s.v. bank).

$\mathbf{b a n k}^{2} \boldsymbol{n}$ The banks of a river, canal, or lake are the raised areas of ground along its edge. (COBUILD, 2006, s.v. bank).

Aqui, COBUILD (2006) opta por separar as acepções em verbetes que representam dois grupos, um relativo ao significado "instituição financeira", que abarca inclusive acepções referentes a classes gramaticais distintas, ${ }^{11}$ e um relativo ao significado "margem", adotando uma solução homonímica por critério semântico.

A partir disto, analisamos, no total, nove itens lexicais e constatamos que as obras diferem entre si, de modo significativo, no tratamento do mesmo fenômeno. Por exemplo, em nenhuma das obras a forma de trazer as acepções de lie é a mesma. CALD (2008) adota uma solução polissêmica parcial, ou seja, apresenta um verbete para todas as acepções, mas com divisão interna por classe gramatical. COBUILD (2006) emprega uma solução homonímica por critério semântico e mistura as acepções de diferentes classes gramaticais dentro do verbete. LDCE (2009) emprega uma solução homonímica morfológica, com um verbete para as acepções do verbo e outro para as acepções do substantivo. OALD (2005) adota uma solução homonímica, mas mantém no mesmo verbete as acepções referentes à mesma origem etimológica e divide os verbetes por blocos de acepções de mesma classe gramatical.

Finalmente, outro fato constatado é que, na mesma obra, o mesmo fenômeno é tratado de formas distintas. Por exemplo, as palavras homônimas homófonas case e lie no OALD (2005):

case $n$ SITUATION $1[C]$ a particular situation or a situation of a particular type CONTAINER $\mathbf{7}[\mathrm{C}]$ a container or covering used to protect or store things; a container with its contents or the amount that it contains. (OALD, 2005, s.v. case).

$\operatorname{lie}^{1} \mathbf{1}$ to be or put yourself in a flat or horizontal position so that you are not standing or sitting. (OALD, 2005, s.v. lie).

$\mathbf{l i e}^{2}$ to say or write sth that you know is not true. (OALD, 2005, s.v. lie).

11 Apesar de aqui termos também um caso de solução polissêmica, se forem considerados apenas os significados referentes à "instituição financeira", pois as diferentes classes gramaticais, substantivo e verbo, são apresentadas no mesmo verbete. 
Em ambos os casos, estamos diante de itens lexicais homônimos homófonos, sendo que não há qualquer relação etimológica ou semântica entre os significados. Contudo, no caso de case, OALD (2005) opta por trazer as acepções com uma solução polissêmica total, ou seja, apresenta os significados não relacionados de case em um verbete único. Já quanto à palavra lie, que também é um homônimo homófono, OALD (2005) emprega uma solução homonímica por critério semântico ou etimológico. Mesmo que sejam itens lexicais de classes gramaticais distintas, a solução utilizada pela obra para apresentar os verbetes não parece seguir critérios sistemáticos.

As soluções empregadas por cada obra em cada um dos verbetes dos itens lexicais são sintetizadas no quadro abaixo (os itens estão divididos em homônimos e polissêmicos, para evidenciar as diferenças entre um tratamento lexicológico e lexicográfico):

\section{Quadro 2 - Análise geral da solução adotada por cada dicionário nos verbetes por item lexical}

\begin{tabular}{|c|c|c|c|c|c|}
\hline & $\begin{array}{c}\text { Item } \\
\text { lexical }\end{array}$ & $\begin{array}{l}\text { CALD } \\
(2008)\end{array}$ & $\begin{array}{c}\text { COBUILD } \\
(2006)\end{array}$ & $\begin{array}{l}\text { LDCE } \\
(2009)\end{array}$ & $\begin{array}{l}\text { OALD } \\
(2005)\end{array}$ \\
\hline \multirow[t]{4}{*}{$\begin{array}{l}\text { Itens } \\
\text { lexicais } \\
\text { homônimos } \\
\text { homógrafos } \\
\text { homófonos }\end{array}$} & band & $\begin{array}{l}\text { solução polissê- } \\
\text { mica e não apre- } \\
\text { senta outra clas- } \\
\text { se gramatical }\end{array}$ & $\begin{array}{l}\text { solução polissê- } \\
\text { mica e não apre- } \\
\text { senta outra clas- } \\
\text { se gramatical }\end{array}$ & $\begin{array}{l}\text { solução homo- } \\
\text { nímica morfoló- } \\
\text { gica }\end{array}$ & $\begin{array}{l}\text { solução polissê- } \\
\text { mica com divi- } \\
\text { são interna do } \\
\text { verbete por clas- } \\
\text { se gramatical }\end{array}$ \\
\hline & bank & $\begin{array}{l}\text { solução polissê- } \\
\text { mica com divi- } \\
\text { são interna do } \\
\text { verbete por clas- } \\
\text { se gramatical }\end{array}$ & $\begin{array}{l}\text { solução homoní- } \\
\text { mica e mistura } \\
\text { as classes gra- } \\
\text { maticais no ver- } \\
\text { bete }\end{array}$ & $\begin{array}{l}\text { solução homo- } \\
\text { nímica morfoló- } \\
\text { gica }\end{array}$ & $\begin{array}{l}\text { solução polissê- } \\
\text { mica com divi- } \\
\text { são interna do } \\
\text { verbete por clas- } \\
\text { se gramatical }\end{array}$ \\
\hline & case & $\begin{array}{l}\text { solução polissê- } \\
\text { mica e não apre- } \\
\text { senta outra clas- } \\
\text { se gramatical }\end{array}$ & $\begin{array}{l}\text { solução homoní- } \\
\text { mica e não apre- } \\
\text { senta outra clas- } \\
\text { se gramatical }\end{array}$ & $\begin{array}{l}\text { solução homo- } \\
\text { nímica morfoló- } \\
\text { gica }\end{array}$ & $\begin{array}{l}\text { solução polissê- } \\
\text { mica com divi- } \\
\text { são interna do } \\
\text { verbete por clas- } \\
\text { se gramatical }\end{array}$ \\
\hline & lie & $\begin{array}{l}\text { solução polissê- } \\
\text { mica com divi- } \\
\text { são interna do } \\
\text { verbete por clas- } \\
\text { se gramatical }\end{array}$ & $\begin{array}{l}\text { solução homoní- } \\
\text { mica e mistura } \\
\text { as classes gra- } \\
\text { maticais no ver- } \\
\text { bete }\end{array}$ & $\begin{array}{l}\text { solução homo- } \\
\text { nímica morfoló- } \\
\text { gica }\end{array}$ & $\begin{array}{l}\text { solução homoní- } \\
\text { mica e com di- } \\
\text { visão interna do } \\
\text { verbete por clas- } \\
\text { se gramatical }\end{array}$ \\
\hline
\end{tabular}




\begin{tabular}{|c|c|c|c|c|c|}
\hline & \begin{tabular}{|c|} 
Item \\
lexical
\end{tabular} & $\begin{array}{l}\text { CALD } \\
(2008)\end{array}$ & $\begin{array}{l}\text { COBUILD } \\
\text { (2006) }\end{array}$ & $\begin{array}{l}\text { LDCE } \\
(2009)\end{array}$ & $\begin{array}{l}\text { OALD } \\
(2005)\end{array}$ \\
\hline \multirow{5}{*}{$\begin{array}{l}\text { Itens lexi- } \\
\text { cais polissê- } \\
\text { micos }\end{array}$} & accident & $\begin{array}{l}\text { solução polissê- } \\
\text { mica }\end{array}$ & $\begin{array}{l}\text { solução polissê- } \\
\text { mica }\end{array}$ & $\begin{array}{l}\text { solução polissê- } \\
\text { mica }\end{array}$ & $\begin{array}{l}\text { solução polissê- } \\
\text { mica }\end{array}$ \\
\hline & branch & $\begin{array}{l}\text { solução polissê- } \\
\text { mica com divi- } \\
\text { são interna do } \\
\text { verbete por clas- } \\
\text { se gramatical }\end{array}$ & $\begin{array}{l}\text { solução polissê- } \\
\text { mica e não apre- } \\
\text { senta outra clas- } \\
\text { se gramatical }\end{array}$ & $\begin{array}{l}\text { solução homo- } \\
\text { nímica morfoló- } \\
\text { gica }\end{array}$ & $\begin{array}{l}\text { solução polissê- } \\
\text { mica com divi- } \\
\text { são interna do } \\
\text { verbete por clas- } \\
\text { se gramatical }\end{array}$ \\
\hline & close & $\begin{array}{l}\text { solução polissê- } \\
\text { mica com divi- } \\
\text { são interna do } \\
\text { verbete por clas- } \\
\text { se gramatical }\end{array}$ & $\begin{array}{l}\text { solução homoní- } \\
\text { mica morfológi- } \\
\text { ca e pela exten- } \\
\text { são dos verbetes }\end{array}$ & $\begin{array}{l}\text { solução homoní- } \\
\text { mica morfológi- } \\
\text { ca e pela exten- } \\
\text { são dos verbetes }\end{array}$ & $\begin{array}{l}\text { solução homoní- } \\
\text { mica morfológi- } \\
\text { ca e pela exten- } \\
\text { são dos verbetes }\end{array}$ \\
\hline & fresh & $\begin{array}{l}\text { solução polissê- } \\
\text { mica }\end{array}$ & $\begin{array}{l}\text { solução polissê- } \\
\text { mica }\end{array}$ & $\begin{array}{l}\text { solução polissê- } \\
\text { mica }\end{array}$ & $\begin{array}{l}\text { solução polissê- } \\
\text { mica }\end{array}$ \\
\hline & reason & $\begin{array}{l}\text { solução polissê- } \\
\text { mica com divi- } \\
\text { são interna do } \\
\text { verbete por clas- } \\
\text { se gramatical }\end{array}$ & $\begin{array}{l}\text { solução polissê- } \\
\text { mica com clas- } \\
\text { ses gramaticais } \\
\text { misturadas no } \\
\text { mesmo verbete }\end{array}$ & $\begin{array}{l}\text { solução homo- } \\
\text { nímica morfoló- } \\
\text { gica }\end{array}$ & $\begin{array}{l}\text { solução polissê- } \\
\text { mica com divi- } \\
\text { são interna do } \\
\text { verbete por clas- } \\
\text { se gramatical }\end{array}$ \\
\hline
\end{tabular}

Fonte: Oliveira (2010, p.103).

\section{Organização das acepções}

A polissemia e a homonímia impõem que haja uma escolha pela forma de organizar os significados presentes no verbete, ou seja, escolher de qual modo agrupá-los e ordená-los (RAVIN; LEACOCK, 2000). Neste trabalho, focamos nossas análises nesse tópico, que diz respeito ao emprego de um critério que permita dispor e apresentar informação sobre as acepções do item lexical ao consulente, que esteja em consonância com o perfil de usuário e a função da obra. Na Lexicografia, podem ser empregados diversos critérios para a ordenação das acepções, como o critério cronológico e o de frequência. Segundo Werner (1982), no critério cronológico, os sememas de um item lexical são listados a partir da diacronia da língua, da acepção diacronicamente mais antiga até a 
diacronicamente mais recente ou com documentação mais recente. Já no critério de frequência, os sememas relativos a um significante seriam apresentados seguindo a ordem de frequência com que são utilizados na língua. Contudo, não há um critério de organização que seja considerado correto para ser empregado em determinada obra, porém, o que podemos avaliar é se um critério é ou não pertinente para ser aplicado.

Nos learner's dictionaries, buscamos avaliar de que forma se dava essa organização microestrutural. Buscamos informações no front matter das obras que pudessem ser utilizadas para determinar qual critério cada um dos dicionários empregava. Encontramos dois panoramas: o CALD (2008) e o LDCE (2009) explicitamente empregavam a frequência para a ordenação das acepções, enquanto que o COBUILD (2006) e o OALD (2005) não explicitavam o critério empregado, mas, pelas afirmações contidas nos dicionários, depreendemos que também se trata de frequência. Em Oliveira (2010a), analisamos a organização das acepções em verbetes de seis itens lexicais dessas obras - accident, band, branch, close, fresh e reason.

Neste trabalho, apresentamos de forma mais detalhada a análise do item lexical band. No quadro abaixo, são trazidas as acepções de band contidas nos verbetes das quatro obras analisadas (marcamos com a mesma cor as acepções que representam conteúdos semânticos equivalentes, de modo a perceber quais significados são semanticamente correspondentes):

\section{Quadro 3 - Acepções de band nos dicionários analisados}

\begin{tabular}{|c|c|c|c|}
\hline CALD (2008) & COBUILD (2006) & LDCE (2009) & OALD (2005) \\
\hline $\begin{array}{l}\text { MUSICIANS } 1 \text { [C, + } \\
\text { sing/pl verb] a group } \\
\text { of musicians who } \\
\text { play modern music } \\
\text { together }\end{array}$ & \multirow[t]{2}{*}{$\begin{array}{l}1 \text { N-COUNT-COLL } \\
\text { A band is a small } \\
\text { group of musicians } \\
\text { who play popular mu- } \\
\text { sic such as jazz, rock, } \\
\text { or pop. }\end{array}$} & \multirow[t]{2}{*}{$\begin{array}{l}\text { 1APM [also + plural } \\
\text { verb] BrE a group of } \\
\text { musicians, especial- } \\
\text { ly a group that plays } \\
\text { popular music }\end{array}$} & \multirow{2}{*}{$\begin{array}{l}\text { GROUP OF MUSI- } \\
\text { CIANS } \mathbf{1}[\mathrm{C}+\text { sing./pl. } \\
\text { v.] a small group of } \\
\text { musicians who play } \\
\text { popular music to- } \\
\text { gether, often with a } \\
\text { singer or singers } \\
\mathbf{2}[C+\text { sing./pl. V.] a } \\
\text { group of musicians } \\
\text { who play brass and } \\
\text { percussion instruments } \\
\text { EXT.1 }\end{array}$} \\
\hline $\begin{array}{l}\mathbf{2} \text { boy/girl band a } \\
\text { group of fashionable } \\
\text { young men or wom- } \\
\text { en who perform pop- } \\
\text { ular songs together } \\
\text { and dance as a group } \\
\text { EXT.1 }\end{array}$ & & & \\
\hline
\end{tabular}




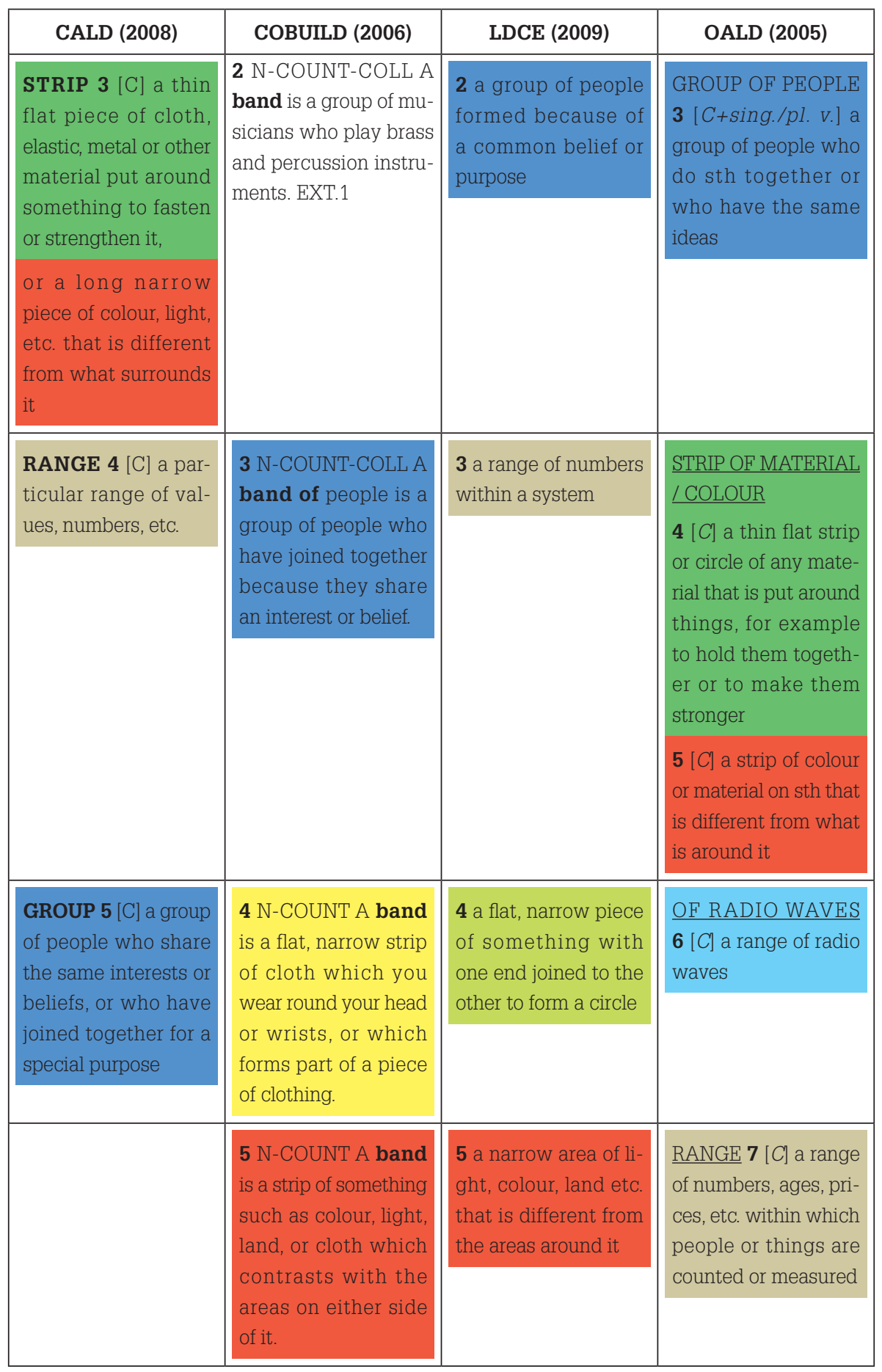




\begin{tabular}{|l|l|l|l|}
\hline CALD (2008) & COBUILD (2006) & LDCE (2009) & OALD (2005) \\
\hline & $\begin{array}{l}\text { 6 N-COUNT A band } \\
\text { is a strip or loop of } \\
\text { metal or other strong } \\
\text { m a terial w hich } \\
\text { strengthens some- } \\
\text { thing, or which holds } \\
\text { several things toge- } \\
\text { ther. }\end{array}$ & $\begin{array}{l}\text { 6 technical a range of } \\
\text { radio signals }\end{array}$ & \\
\hline & $\begin{array}{l}\text { 7 N-COUNT A band } \\
\text { is a range of numbers } \\
\text { or values within a } \\
\text { system of measure- } \\
\text { ment. }\end{array}$ & & \\
\hline
\end{tabular}

Fonte: Oliveira (2010a, p.114).

Para classificar os significados das obras, aplicamos a seguinte codificação:

\section{Quadro 4 - Correspondência entre os significados de band e as acepções apresentadas pelos dicionários}

\begin{tabular}{|l|l|}
\hline Significados & Cor \\
\hline "músicos" & \\
\hline "bando" & \\
\hline "faixa/amarra" & \\
\hline "faixa/aro" & \\
\hline "faixa/parte de vestimenta" & \\
\hline "listra" & \\
\hline "faixa de sintonização" & \\
\hline "faixa de escala" & \\
\hline
\end{tabular}

Fonte: Oliveira (2010a, p.115). 
Ao avaliar de modo geral os quatro verbetes, notamos, primeiramente, que não há uma equivalência total entre os significados trazidos pelas obras. Por exemplo, para os significados relativos a "músicos", CALD (2008) apresenta acepções para "músicos" e para a expressão "boy band", subsumidos à mesma guideword; COBUILD (2006) apresenta "músicos" e "músicos de metais e percussão" como duas acepções distintas, sem qualquer hierarquia entre elas; LDCE (2009) conta apenas com o significado "músicos" e OALD (2005) traz "músicos" e "músicos de metais e percussão" inseridos na mesma guideword. Dessa forma, além de terem acepções diferentes, as obras apresentam tais acepções de maneira também distinta. Isso pode ser esquematizado conforme o quadro a seguir:

\section{Quadro 5 - Significados de "músicos" do item band apresentados pelos dicionários}

\begin{tabular}{|l|l|l|l|}
\hline CALD (2008) & COBUILD (2006) & LDCE (2009) & OALD (2005) \\
\hline \multirow{2}{*}{$\begin{array}{l}\text { "músicos" } \\
\text { "boy band" }\end{array}$} & "músicos" & "músicos" & $\begin{array}{l}\text { "músicos" } \\
\text { "músicos de metais } \\
\text { e percussão" }\end{array}$ \\
\cline { 2 - 3 } & $\begin{array}{l}\text { "músicos de metais } \\
\text { e percussão" }\end{array}$ & & \\
\hline
\end{tabular}

Fonte: Oliveira (2010a, p.115).

Nesses significados, especificamente, estamos diante de um caso de especialização, em que "músicos" é hiperônimo dos outros dois significados ("boy band" e "músicos de metais e percussão") e, caso os dicionários escolhessem incluir esses significados no verbete, deveriam estes estar atrelados hierarquicamente abaixo de "músicos".

Outro ponto importante nesta primeira análise diz respeito às diferenças (por vezes sutis) entre os conteúdos semânticos veiculados por cada definição. Considere as acepções para o significado "faixa" trazidas pelas obras, no quadro abaixo: 
Quadro 6 - Acepções do significado "faixa" nos dicionários

\begin{tabular}{|c|c|c|c|}
\hline CALD (2008) & COBUILD (2006) & LDCE (2009) & OALD (2005) \\
\hline \multirow{2}{*}{$\begin{array}{l}\text { a thin flat piece of } \\
\text { cloth, elastic, metal } \\
\text { or other material put } \\
\text { around something to } \\
\text { fasten or strengthen } \\
\text { it, or a long narrow } \\
\text { piece of eolour, light, } \\
\text { etc. that is different } \\
\text { from what surrounds } \\
\text { it }{ }^{12}\end{array}$} & $\begin{array}{l}\text { A band is a strip } \\
\text { or loop of metal or } \\
\text { other strong material } \\
\text { which strengthens } \\
\text { something, or which } \\
\text { holds several things } \\
\text { together. }\end{array}$ & \multirow[t]{2}{*}{$\begin{array}{l}\text { a flat, narrow piece } \\
\text { of something with } \\
\text { one end joined to the } \\
\text { other to form a circle }\end{array}$} & \multirow[t]{2}{*}{$\begin{array}{l}\text { a thin flat strip or } \\
\text { circle of any material } \\
\text { that is put around } \\
\text { things, for exam- } \\
\text { ple to hold them } \\
\text { together or to make } \\
\text { them stronger }\end{array}$} \\
\hline & $\begin{array}{l}\text { A band is a flat, } \\
\text { narrow strip of cloth } \\
\text { which you wear } \\
\text { round your head } \\
\text { or wrists, or which } \\
\text { forms part of a piece } \\
\text { of clothing. }\end{array}$ & & \\
\hline
\end{tabular}

Fonte: Oliveira (2010a, p.116).

CALD (2008) traz acepção para o significado "faixa/amarra". COBUILD (2006), por sua vez, apresenta duas definições relacionadas ao significado "faixa", uma com o significado de "faixa/amarra" e outra com o significado que chamamos "faixa/parte de vestimenta". LDCE (2009) traz uma acepção com conteúdo diferente, que abrange os significados "faixa/aro". OALD (2005) inclui dois significados, "faixa/amarra" e "faixa/aro", na mesma definição, utilizando-se do recurso da conjunção or e citando um dos possíveis usos (for example) de tais faixas, mas não excluindo outros. Desse modo, temos o seguinte panorama com relação às acepções vinculadas ao significado "faixa":

\section{Quadro 7 - Significados "faixa/amarra", "faixa/aro" e "faixa/parte de vestimenta" nos dicionários}

\begin{tabular}{|c|c|c|c|}
\hline CALD (2008) & COBUILD (2006) & LDCE (2009) & OALD (2005) \\
\hline \multirow[b]{2}{*}{ "faixa/amarra" } & "faixa/amarra" & \multirow[b]{2}{*}{ "faixa/aro" } & \multirow{2}{*}{$\begin{array}{l}\text { "faixa/amarra" + } \\
\text { "faixa/aro" }\end{array}$} \\
\hline & $\begin{array}{l}\text { "faixa/parte de } \\
\text { vestimenta" }\end{array}$ & & \\
\hline
\end{tabular}

Fonte: Oliveira (2010a, p.116).

12 A segunda parte da definição contida em CALD (2008) não será considerada, por se referir a um significado distinto (que aqui chamamos de "listra"). 
Mesmo desconsiderando as diferenças entre os significados contidos em cada obra, fica evidente que, caso todos os dicionários analisados utilizassem como critério de ordenação das acepções a frequência, eles deveriam apresentar as acepções correlatas na mesma ordem, mesmo que houvesse, nas obras, tais diferenças entre os significados. Contudo, notamos que mesmo as duas obras que explicitamente afirmam que ordenam as acepções por frequência (CALD, 2008; LDCE, 2009) têm acepções que vinculam o mesmo conteúdo semântico em ordens distintas. No caso, por exemplo, de compararmos a ordem em que são apresentados os significados "faixa/amarra", "listra" e "bando", percebemos, ainda, que ela é oposta. Esses dados são trazidos no quadro abaixo:

\section{Quadro 8 - Significados "faixa/amarra", "listra" e "bando" nos dicionários}

\begin{tabular}{|l|l|}
\hline CALD (2008) & LDCE (2009) \\
\hline "faixa/amarra" + "listra" & "bando" \\
\hline \multirow{2}{*}{ "bando" } & "faixa/aro" \\
\cline { 2 - 2 } & "listra" \\
\hline
\end{tabular}

Fonte: Oliveira (2010a, p.117).

Poderíamos supor que a diferença entre a ordem das acepções "faixa/amarra" e "listra" de CALD (2008) e "faixa/aro" e "listra" de LDCE (2009) tenha sido pela junção que CALD (2008) faz desses significados. Por tal motivo em uma obra esses significados apareceriam antes de "bando" e, na outra, depois. Porém, como CALD (2008) afirma que a ordenação das acepções é feita a partir do primeiro significado subsumido a uma guideword, ou seja, neste caso, a partir do significado "faixa/ amarra", essa hipótese não se sustenta. Nesse caso, não estaríamos considerando a frequência de "faixa/amarra" mais a frequência de "listra", porém apenas a do primeiro deles. Contudo, a diferença entre o conteúdo semântico das duas acepções pode ter influenciado nessa ordenação, pois, enquanto CALD (2008) representa o significado de "faixa/amarra", LDCE (2009) apresenta o de "faixa/ aro", que tem uma aplicação muito mais restrita.

Outro exemplo dessa diferença na ordenação das acepções entre os dicionários que utilizam explicitamente a frequência é o dos significados "bando" e "faixa de escala". CALD (2008) apresenta a ordem "bando" e "faixa de escala", enquanto que as mesmas acepções são trazidas em ordem inversa em LDCE (2009), e tais acepções têm exatamente o mesmo conteúdo semântico nas definições das duas obras. 
Apresentamos, abaixo, um quadro comparativo da ordenação dos significados apresentada por cada obra:

\section{Quadro 9 - Correspondência entre significados de band, as acepções apresentadas pelos dicionários}

\begin{tabular}{|l|l|l|l|}
\hline \multicolumn{2}{|c|}{$\begin{array}{c}\text { Dicionários com critério } \\
\text { de frequência }\end{array}$} & \multicolumn{2}{c|}{$\begin{array}{c}\text { Dicionários sem referência } \\
\text { explícita de critério }\end{array}$} \\
\hline CALD (2008) & LDCE (2009) & COBUILD (2006) & OALD (2005) \\
\hline "músicos" & "músicos" & "músicos" & "músicos" \\
\hline $\begin{array}{l}\text { "faixa/amarra e } \\
\text { listra" }\end{array}$ & "bando" & "bando" & "bando" \\
\hline "faixa de escala" & "faixa de escala" & $\begin{array}{l}\text { "faixa/parte de } \\
\text { vestimenta" }\end{array}$ & "faixa/amarra"+"listra" \\
\hline "bando" & "faixa/aro" & "listra" & "faixa de sintonização" \\
\hline & "listra" & "faixa/amarra" & "faixa de escala" \\
\hline & "faixa de sintonização" & "faixa de escala" & \\
\hline
\end{tabular}

Fonte: Oliveira (2010a, p.117).

Avaliamos as obras que não explicitam os critérios de organização dos verbetes - COBUILD (2006) e OALD (2005) - com o intuito de definir qual critério cada uma delas utiliza para a ordenação das acepções. ${ }^{13}$ Para tanto, partimos das seguintes hipóteses:

(a) Critério de prototipicidade: primeiro seriam apresentados os significados mais básicos e concretos (ou mais gerais), seguidos por significados mais abstratos que caracterizariam extensões desses núcleos mais concretos;

(b) Critério etimológico: as acepções estariam divididas de acordo com a classificação do item em polissêmico ou homonímico (ou seja, se existem diferentes formas que dão origem aos significados do item lexical) e, a partir da acepção reta, as acepções figuradas seriam introduzidas conforme seu desenvolvimento histórico;

(c) Critério de frequência: se esse fosse o critério empregado, as quatro obras não apresentariam divergências quanto à disposição das acepções (ou, pelo menos, em comparação com os outros dicionários que também utilizassem

13 Na verdade, com essas análises, buscamos mostrar que esses critérios não tinham sido utilizados, de modo a restar apenas o critério de frequência, para o qual já tínhamos indícios no front matter das obras. 
a frequência como critério), visto que cada uma delas utiliza um corpus representativo para pesquisa e emprega critérios e metodologia sistemáticos para a delimitação dos significados dos itens lexicais e seu reconhecimento no corpus.

Quanto aos critérios utilizados para a ordenação das acepções, a primeira possibilidade de emprego por parte de COBUILD (2006) é a prototipicidade. Porém, ao analisar as duas primeiras acepções ("músicos" e "bando"), essa hipótese já é descartada. Isso porque, caso esse fosse o critério empregado, a acepção "bando" deveria ser apresentada antes de "músicos" e a relação existente entre esses dois significados deveria ser representada graficamente de modo distinto da especialização "músicos de metais e percussão". A relação entre os significados "bando" e "músicos" e entre "músicos" e "músicos de metais e percussão" é de ordem distinta. No primeiro caso, temos uma extensão de significado, no segundo, uma relação de hiperonímia e hiponímia. Além disso, COBUILD (2006) traz o significado "faixa/parte de vestimenta" antes de "faixa", o que também não é compatível com o critério de prototipicidade.

A segunda possibilidade de critério utilizada por COBUILD (2006) para o ordenamento é a etimologia. Tal estruturação seria, por um lado, impossível, pois etimologicamente o item lexical possui três origens distintas, o que tornaria sua representação inviável a partir de uma solução polissêmica. Porém, caso o dicionário optasse por apresentar as acepções a partir de uma solução polissêmica, mas com agrupamento a partir da etimologia, ainda assim a obra traria a definição de "bando" antes de "músicos" e "faixa/amarra" antes de "faixa/parte de vestimenta", por serem etimologicamente anteriores (OED, 1933, s.v. band). O último critério que abordaremos para essa obra é o de frequência, que será analisado separadamente mais adiante.

Quanto ao OALD (2005), começamos pelo critério de prototipicidade. Apesar de a obra trazer as acepções "músicos" e "músicos de metais e percussão" na mesma guideword (organização compatível com uma estruturação prototípica), a acepção "bando" deveria anteceder a acepção "músicos". Além disso, mesmo que os significados "faixa" e "listra" figurassem na mesma acepção, os outros significados, "faixa de sintonização" e "faixa de escala", deveriam estar graficamente representados como extensões desses primeiros significados, hierarquicamente abaixo de "faixa" e "listra", mas na mesma estrutura (nesse caso, na mesma guideword).

Quanto à utilização do critério etimológico em OALD (2005), ocorre o mesmo que em COBUILD (2006). Por um lado, deveria ter sido empregada uma solução homonímica e, por outro, a ordem na qual as acepções são apresentadas descarta a utilização desse critério. 
Tendo em vista que os dois primeiros critérios analisados não foram suficientes para determinar qual o modo de organização das acepções, partimos para a análise do critério de frequência. Para tanto, utilizamos dois corpora disponíveis on-line, ${ }^{14}$ o Collins Wordbanks Online English corpus (CWB - parte do corpus utilizado para a confecção do COBUILD) e o British National Corpus (BNC - corpus utilizado para a redação do OALD), nos quais buscamos ocorrências do item lexical band.

O primeiro deles fornece dois tipos de opção de busca, uma que realiza a pesquisa em todos os sub-corpora integrantes do CWB e uma que permite a busca em cada um dos três sub-corpora que o compõem de modo individual. Os sub-corpora do CWB são o British books, ephemera, radio, newspapers, magazines (composto por 36 milhões de palavras), o American books, ephemera and radio (10 milhões de palavras) e o British transcribed speech (10 milhões de palavras). A ferramenta de busca do CWB fornece 40 ocorrências por busca e os resultados de pesquisa são dispostos por ordem de catalogação (não randômica), ou seja, o texto em que o item lexical aparece e que estiver primeiro na ordem de busca será de onde os alinhamentos serão extraídos. Desse modo, ele não permite buscas consecutivas para o mesmo item lexical que gerem resultados diferentes.

O BNC é composto por 100 milhões de palavras e compreende textos do inglês britânico do final do século XX até os dias atuais, sendo que 90\% deles se referem a textos escritos. Nesse corpus, ao pesquisar pelos usos de um item, abre-se uma tela com 50 alinhamentos selecionados de modo randômico pela ferramenta. Acima dos alinhamentos, é informado o número total de ocorrências brutas do item pesquisado no corpus, que, por exemplo, para o item lexical accident, consistia em 6300 ocorrências. Além disso, cada um dos alinhamentos é antecedido pelo código da referência do texto do qual ele foi extraído, sendo essa informação acessível a quem faz a busca. ${ }^{15}$

Ambos os corpora utilizados nas análises são ferramentas gratuitas, disponíveis on-line e são disponibilizados apenas de forma parcial, não sendo possível o acesso a todos os seus recursos, o que pode ter trazido interferência aos resultados.

No BNC, o número total de ocorrências brutas do item lexical band foi de 6659. Realizamos duas buscas consecutivas, de modo que obtivemos 100 ocorrências para análise. No CWB, por sua vez, buscamos pelo item lexical três vezes, uma vez em cada sub-corpus, obtendo, no total, 120 ocorrências de uso do item.

14 Cabe lembrar que os dados apresentados aqui dizem respeito a buscas realizadas durante o início de 2010. Não descartamos a possibilidade de que os corpora já tenham sofrido alterações.

15 Ao buscar, por exemplo, por accident e ficar em dúvida com relação a qual significado estava sendo utilizado em determinado alinhamento, era possível que o título ou tipo de publicação auxiliasse a decidir qual significado melhor se encaixava no contexto de uso. 
Apresentamos, no quadro abaixo, exemplos de ocorrência para cada um dos significados do item lexical band extraídos dos corpora analisados.

\section{Quadro 10 - Significados apresentados nos quatro dicionários e exemplos de ocorrências nos corpora}

\begin{tabular}{|l|l|l|}
\hline Significado & Corpus & Exemplo de uso nos corpora \\
\hline "músicos" & CWB & $\begin{array}{l}\text { A real band playing real music with passion, } \\
\text { irreverence [...] }\end{array}$ \\
\hline "bando" & BNC & $\begin{array}{l}\text { And it's nothing more than what they deserve, for } \\
\text { they're a band of turncoats. }\end{array}$ \\
\hline "faixa/amarra" & BNC & $\begin{array}{l}{[\ldots] \text { a jam jar with a bunch of freesias still bound with }} \\
\text { a rubber band. }\end{array}$ \\
\hline "faixa/aro" & CWB & $\begin{array}{l}{[\ldots] \text { Claire prodded her wedding band with the tip }} \\
\text { of her thumb [...] }\end{array}$ \\
\hline $\begin{array}{l}\text { "faixa/parte de } \\
\text { vestimenta" }\end{array}$ & BNC & $\begin{array}{l}\text { The woman was in a white dress [...] and thin } \\
\text { goldened hair in a page-boy cut with a white band } \\
\text { round it to match the dress [...] }\end{array}$ \\
\hline "listra" & CWB & $\begin{array}{l}{[\ldots] \text { Choose Natural or White with a band of color in }} \\
\text { Colonial Green, Blue, Rose [...] }\end{array}$ \\
\hline "faixa de sintonização" & CWB & $\begin{array}{l}{[\ldots] \text { The Arizona State Police band was transmitting }} \\
\text { a description of a truck [...]. }\end{array}$ \\
\hline "faixa de escala" & CWB & $\begin{array}{l}\text { use the figures for pupil numbers per age band which } \\
\text { the authority had obtained [...] }\end{array}$ \\
\hline
\end{tabular}

Fonte: Adaptado de Oliveira (2010a, p.120).

Um grande número de ocorrências não foi considerado para a análise, devido aos fatos de (i) não ter sido possível determinar o significado atualizado por falta de contexto; (ii) o item lexical estar inserido em um nome próprio; (iii) participar de uma expressão sintagmática; (iv) estar sendo utilizado em outra categoria gramatical e (v) ser um uso técnico.

Classificamos cada uma das ocorrências dos corpora com base nos significados apresentados pelos dicionários. Temos, na tabela abaixo, a classificação quantitativa dos dois corpora, considerando tanto os significados analisados quanto os casos que não foram utilizados para a análise de frequência. 
Tabela 1 - Dados quantitativos da análise das ocorrências de band

\begin{tabular}{lcccccc} 
Significado & BNC & $\begin{array}{l}\text { Posição } \\
\text { no BNC }\end{array}$ & CWB & $\begin{array}{l}\text { Posição } \\
\text { no CWB }\end{array}$ & $\begin{array}{l}\text { Total nos } \\
\text { dois corpora }\end{array}$ & $\begin{array}{l}\text { Posição } \\
\text { total }\end{array}$ \\
\hline "músicos" & 46 & 1 & 49 & 1 & 95 & 1 \\
"bando" & 9 & 2 & 11 & 2 & 20 & 2 \\
"faixa/amarra" & 1 & 6 & 5 & 3 & 6 & 5 \\
$\begin{array}{l}\text { "faixa/aro" } \\
\text { "faixa/parte de }\end{array}$ & 1 & 6 & 1 & 5 & 2 & 7 \\
$\begin{array}{l}\text { vestimenta" } \\
\text { "listra" }\end{array}$ & 3 & 4 & 5 & 3 & 8 & 3 \\
"faixa de & 1 & 6 & 1 & 5 & 2 & 7 \\
sintonização" & 6 & 3 & 2 & 4 & 8 & 3 \\
"faixa de escala" & 2 & 5 & 1 & 5 & 3 & 6 \\
$\begin{array}{l}\text { Não analisados } \\
\text { Total de ocorrências }\end{array}$ & 10 & - & 45 & - & 76 & - \\
\hline
\end{tabular}

Fonte: Oliveira (2010a, p.121).

A partir dos dados, fica evidente que a consideração dos corpora, tanto individualmente quanto de modo conjunto, não foi totalmente compatível com a ordenação das acepções apresentada pelas obras. Se considerássemos apenas os dois significados mais frequentes obtidos nas análises dos corpora, perceberíamos que eles estão de acordo com a ordenação de LDCE (2009) e OALD (2005), porém, não poderíamos afirmar com precisão se realmente esse é o caso. Desse modo, não conseguimos determinar quais critérios foram realmente empregados por cada obra para a ordenação das acepções, mas podemos afirmar que nenhuma das obras empregou os critérios de prototipicidade e etimologia, e o critério de frequência como recurso objetivo não parece, tampouco, ter sido empregado.

Em uma análise sistemática, em Oliveira (2010a), avaliamos os itens lexicais accident, branch, close, fresh e reason nos mesmos moldes da análise apresentada acima. A partir de nossas análises, evidenciamos a existência dos seguintes problemas: (i) diferentes significados são trazidos para o mesmo item lexical pelas obras; (ii) o modo de separar as acepções é, às vezes, distinto em cada um dos dicionários e, (iii) por vezes, o conteúdo semântico vinculado pelas definições é diferente para o mesmo significado. Tais questões são anteriores à discussão da 
ordenação das acepções, porém podem influenciar consideravelmente em sua disposição.

Quanto à ordenação das acepções propriamente dita, percebemos que: (i) dificilmente os significados são ordenados da mesma forma nas obras; (ii) os dicionários que explicitamente utilizam a frequência como critério de ordenação das acepções - CALD (2008) e LDCE (2009) - ordenam as acepções de forma bastante divergente; (iii) as outras duas obras - COBUILD (2006) e OALD (2005) -, que não explicitam os critérios empregados, divergem entre si e em comparação com as outras duas; (iv) se considerarmos que a ordenação nos quatro dicionários foi feita por frequência, os resultados encontrados a partir das análises dos corpora, na maioria dos casos, divergem da ordenação presente nas obras.

Conforme apresentado em Oliveira (2010c), imaginamos que esses problemas podem ter surgido pela própria utilização do critério de frequência para a ordenação das acepções. Isso porque, por um lado, a representatividade de um corpus não tem como ser objetivamente determinada, ou seja, não há como estabelecer quantitativamente a extensão de uma amostra para que ela seja considerada representativa (SARDINHA, 2004). Mesmo que sejam consideradas as três dimensões de extensão de um corpus (o número de palavras, o número de textos e o número de gêneros) para sua confecção, "[...] o ônus de demonstrar a representatividade da amostra e de ser cuidadoso em relação à generalização dos seus achados para uma população inteira [...] é dos usuários." (SARDINHA, 2004, p.25).

Essa característica faz com que a utilização de corpora diferentes para a análise da frequência das acepções possa originar resultados também diferentes (LEW, 2009; COCK; GRANGER, 2004). Segundo Lew (2009), além do problema da composição do corpus, nesse tipo de ordenação ainda existe a questão da avaliação humana, pois, como não existem métodos automáticos de reconhecimento de significado, essa análise é feita manualmente e está sujeita à subjetividade. Por fim, o autor aponta que pouco se sabe ou foi demonstrado a respeito da pertinência desse tipo de ordenação para os usuários dos dicionários.

Além disso, quando se utiliza esse material para analisar a frequência com que os significados são utilizados, dificilmente todas as ocorrências seriam avaliadas, pois só o item lexical accident, por exemplo, apresenta 6300 ocorrências no BNC, o que tornaria humana e financeiramente inviável que, para todos os itens lexicais, houvesse a classificação de todos os contextos de ocorrência a partir dos significados delimitados. Faz-se, na verdade, um recorte dessas ocorrências de modo randômico. Desse modo, torna-se necessário que sejam feitos estudos para determinar como esse recorte (recorte do corpus, que já é um recorte) pode ser representativo - se é que pode - e quantas ocorrências deveriam ser julgadas para 
uma análise quantitativa dos significados empregados. Essa questão quantitativa é um problema que, estruturalmente, não tem como ser resolvido, a não ser que sejam analisados os significados de todas as ocorrências de todo o corpus ${ }^{16}$, ou que estudos lexicométricos apontem precisamente a quantidade de ocorrências apropriadas em cada caso.

Os problemas apresentados pelo critério de frequência são resumidos no quadro abaixo:

\section{Quadro 11 - Problemas apresentados pelo critério de frequência para a ordenação das acepções}

\begin{tabular}{|c|c|c|}
\hline Nível dos problemas & Problemas & Consequências \\
\hline \multirow{3}{*}{$\begin{array}{l}\text { Anteriores à } \\
\text { aplicação do critério } \\
\text { de frequência }\end{array}$} & $\begin{array}{l}\mathbf{1} \text { dicionários apresentam } \\
\text { diferentes significados para o } \\
\text { mesmo item lexical }\end{array}$ & \multirow{3}{*}{$\begin{array}{l}\text { pode tornar impossível a } \\
\text { comparação direta entre os } \\
\text { significados apresentados } \\
\text { pelas obras }\end{array}$} \\
\hline & $\begin{array}{l}2 \text { modo de separar as } \\
\text { acepções dos itens é distinto } \\
\text { em cada um dos dicionários }\end{array}$ & \\
\hline & $\begin{array}{l}3 \text { conteúdo semântico } \\
\text { vinculado pelas definições } \\
\text { é diferente para o mesmo } \\
\text { significado de um item }\end{array}$ & \\
\hline \multirow{3}{*}{$\begin{array}{l}\text { Específicos à } \\
\text { aplicação do critério } \\
\text { de frequência }\end{array}$} & $\begin{array}{l}1 \text { noção de } \\
\text { representatividade de um } \\
\text { corpus }\end{array}$ & $\begin{array}{l}\text { corpora com conteúdos } \\
\text { diferentes e que podem gerar } \\
\text { resultados diferentes }\end{array}$ \\
\hline & 2 avaliação humana & $\begin{array}{l}\text { análise feita manualmente e } \\
\text { sujeita à subjetividade }\end{array}$ \\
\hline & $\begin{array}{l}3 \text { classificação de um recorte } \\
\text { randômico das ocorrências }\end{array}$ & $\begin{array}{l}\text { tenta tornar representativa } \\
\text { uma amostra do que já busca } \\
\text { ser representativo }\end{array}$ \\
\hline
\end{tabular}

Fonte: Oliveira (2010a, 2010c).

Concepção de estrutura semasiológica da Semântica Cognitiva e a organização das acepções nos learner's dictionaries

No panorama semântico-cognitivo, a polissemia suscita questões fundamentais, que vão desde a natureza do significado, a forma como

16 Mesmo assim, a questão da representatividade geral do corpus permanece. 
os significados dos itens lexicais podem ser identificados, enumerados e caracterizados, até problemas relacionados à realidade psicológica dessa organização (TAYLOR, 2003b). A retomada do interesse pelo estudo da polissemia é tida como uma das maiores contribuições da Linguística Cognitiva à Lexicologia, assim como sua busca por incorporar a flexibilidade e a instabilidade do significado em seus modelos de descrição da estrutura semântica (GEERAERTS, 2010).

A polissemia pode ser definida como o fenômeno no qual dois ou mais significados relacionados são associados a uma mesma forma linguística (TAYLOR, 2003b). Nesses casos, a relação mantida entre os significados pode ser descrita com base na noção de motivação, na qual um significado dá origem a outro. A novidade dessa noção é o fato de que, para a Semântica Cognitiva, a motivação se dá por princípios cognitivos gerais, de modo que essa teoria percebe os itens lexicais individualmente "[...] como categorias de significados relacionados que são motivados por princípios cognitivos como metáfora, metonímia, generalização, especialização e transformações por esquemas de imagem." (CUYCKENS; ZAWADA, 2001, p.XIV, tradução nossa). ${ }^{17}$

Nessa abordagem lexical, o modelo de descrição da polissemia se dá a partir da extensão da Teoria Prototípica desenvolvida na psicologia cognitiva por Eleanor Rosch (1999). Para tal modelo lexical, os significados de um item lexical estariam dispostos em agrupamentos de significados inter-relacionados, centrados em torno de um significado (mais básico), no qual efeitos de semelhança de família ${ }^{18}$ [family resemblance] caracterizariam a relação entre os vários significados, com o significado central geralmente combinando o máximo de características salientes (GEERAERTS, 2010).

Abaixo, apresentamos as quatro características apontadas por Geeraerts (1997, 2006a) para as categorias prototípicas: ${ }^{19}$

17 "[...] categories of related senses which are motivated by cognitive principles such as metaphor, metonymy, generalization, specialization, and image-schema transformations."

18 Ou seja, os atributos apresentados não são compartilhados por todos os membros da categoria (significados), mas a categoria seria unida a partir de uma estrutura na qual os atributos se entrecruzam.

19 Cabe salientar que não há consenso sobre a origem desses efeitos na estrutura categorial e que, para ser considerada prototípica, uma categoria não precisa apresentar todas essas características, mas apenas uma delas, normalmente, os diferentes graus de representatividade entre os membros (GEERAERTS, 2006a). 
Quadro 12 - Características das categorias prototípicas.

\begin{tabular}{|l|l|l|}
\hline & $\begin{array}{l}\text { EXTENSIONALMENTE } \\
\text { (a nível referencial) }\end{array}$ & $\begin{array}{l}\text { INTENSIONALMENTE } \\
\text { (a nível dos significados) }\end{array}$ \\
\hline $\begin{array}{l}\text { NÃo IGUALDADE } \\
\text { (efeitos de saliência, } \\
\text { estrutura interna centro } \\
\text { periferia) }\end{array}$ & $\begin{array}{l}\text { (1) graus de } \\
\text { representatividade entre os } \\
\text { membros de uma categoria }\end{array}$ & $\begin{array}{l}\text { (2) agrupamentos } \\
\text { de significados em } \\
\text { "semelhanças de família" } \\
\text { e agrupamentos radiais }\end{array}$ \\
\hline $\begin{array}{l}\text { NÃo DISCRIÇÃo } \\
\text { (problemas de } \\
\text { demarcação, flexibilidade) }\end{array}$ & $\begin{array}{l}\text { (3) flutuações nas margens de } \\
\text { uma categoria }\end{array}$ & $\begin{array}{l}\text { (4) impossibilidade de } \\
\text { definições em termos de } \\
\text { "condições necessárias e } \\
\text { suficientes" }\end{array}$ \\
\hline
\end{tabular}

Fonte: Adaptado de Geeraerts (2006a, p.149).

As relações existentes entre os significados de um item lexical polissêmico são divididas por Geeraerts (1995) em dois grupos: (i) as relações hierárquicas, nas quais os significados podem ser pensados a partir de uma taxonomia, como os casos de generalização e esquematização, e (ii) as relações não hierárquicas, nas quais os significados apresentam uma similaridade parcial, como os casos de metáfora e metonímia.

Geeraerts (2001) afirma que a utilização do modelo prototípico de polissemia auxilia a Metalexicografia a lidar com alguns dos problemas que surgem com a representação da polissemia nos dicionários. Focando-se na problemática da apresentação microestrutural, Geeraerts (2001) destaca que, pela própria linearidade da escrita e consequente linearidade da estrutura de um dicionário, há a impossibilidade de que se represente, em uma estrutura linear de arranjo de acepções, a estrutura cognitiva multidimensional que a polissemia apresenta. Assim, a polissemia dos itens lexicais é afetada pela obrigatoriedade de linearização dos significados imposta pelos dicionários (GEERAERTS, 2001, 2006b). Desse modo, a utilização de uma teoria que perceba a estruturação radialmente agrupada da polissemia é o ponto de partida fundamental para a consideração desse fenômeno no âmbito lexicográfico (GEERAERTS, 2001, 2007). Porém, mesmo com essa dificuldade intrínseca, Geeraerts aponta que existem recursos já utilizados na Lexicografia, mesmo que de maneira não "consciente", para lidar com os problemas levantados pela Teoria Prototípica. O autor cita o recurso a mecanismos como o agrupamento hierárquico, os marcadores semânticos e as remissões como possíveis formas de minimizar os problemas trazidos pela linearização. 
A característica intensional (2) do Quadro 12, ponto central na discussão apresentada neste trabalho, se levada ao âmbito lexicográfico, reflete, por exemplo, na forma como os significados do item estariam relacionados no verbete. $\mathrm{Na}$ descrição da estrutura semasiológica do item, os significados estariam relacionados de forma que existiriam agrupamentos, com significados mais representativos para a estrutura semasiológica dispostos ao centro desses agrupamentos, que serviriam como uma possível base para a extensão dos outros significados. Tanto os significados considerados de forma individual quanto os agrupamentos (grupos de significados) estariam relacionados entre si por semelhanças de família (ou seja, não por um compartilhamento total de atributos), e apresentariam sobreposição semântica.

Por um lado, se a noção de polissemia da Semântica Cognitiva for adotada, é importante que a descrição dos significados dos itens lexicais seja feita levando-se em conta as relações entre os significados e a natureza da estrutura lexical. Desse modo, manter os agrupamentos de significado na estruturação do verbete de um dicionário é fundamental dentro de um modelo que se baseie nessa concepção, de modo que os significados estariam dispostos do mais básico, concreto e literal aos mais específicos e figurados. Além disso, esse tipo de ordenação acabaria com os possíveis problemas do lumping e splitting, pelo menos quanto aos significados relacionados de forma direta. Isso porque, diferentemente da frequência - que separa significados semanticamente relacionados -, uma ordenação com critério semântico-cognitivo tentaria sempre manter os grandes blocos de agrupamento unidos. De tal modo, independentemente de optar pelo lumping ou splitting, os significados apresentariam uma mesma posição, definidos por uma catch-all definition ou discriminados individualmente.

Entendendo que um modelo de descrição semântica não pode ser empregado diretamente no âmbito da Lexicografia, julgamos necessário que o próprio modelo prototípico de polissemia receba um tratamento condizente com o trabalho lexicográfico e que seja pensado a partir dos fatores que determinam a constituição das obras (taxonomia, perfil de usuário e função da obra). Isso posto, na seção abaixo, focamos nossa análise na estrutura semasiológica multidimensional dos itens lexicais, cuja representação deve levar em conta os diferentes tipos de dados que surgem da concepção prototípica de estrutura semântica (GEERAERTS, 1995): os efeitos de saliência entre os significados, as relações não hierárquicas entre os significados, as relações hierárquicas entre os significados e a dificuldade no estabelecimento dos limites da polissemia.

\section{Aplicação ao verbete dos learner's dictionaries}

Quanto à solução adotada, entendemos que, nos learner's dictionaries, a melhor opção a ser empregada é a solução polissêmica parcial (exceto nos 
casos de homônimos não homófonos). Isso porque esse tipo de obra apresenta apenas os significados sincrônicos mais utilizados dos itens lexicais. Dessa maneira, uma solução homonímica etimológica, por exemplo, não parece apropriada, pois não estaria de acordo com os propósitos (sincrônicos) desse tipo de obra e não traria um ganho efetivo ao consulente (por exemplo, separar band em dois verbetes não seria útil para o consulente, mesmo que seja etimologicamente correto). Por outro lado, para verbetes não muito extensos, parece-nos não haver a necessidade de separar itens que apresentem diferentes classes gramaticais em verbetes distintos (ou seja, solução homonímica morfológica), visto que apenas sua apresentação em blocos distintos (uma solução polissêmica parcial), além de poupar espaço, é condizente com o conhecimento linguístico esperado de um aprendiz avançado, pois nesse nível ele já deve possuir habilidade linguística para procurar pela classe gramatical específica do item em questão. Além disso, as discrepâncias semânticas, quando existentes, podem ser acomodadas também com a utilização de blocos distintos dentro do mesmo verbete, antecedidos por alguma marcação, por exemplo, de numerais romanos.

Quanto ao problema da ordenação das acepções nos learner's disctionaries, por todas as questões inerentes à discussão em pauta, frisamos que buscamos com nossas propostas dar um primeiro passo em direção à construção de um modelo mais amplo que permita mediar as noções semântico-cognitivas, como a concepção de polissemia, com vistas a sua aplicação lexicográfica.

Mesmo que, por um lado, a utilização de uma teoria que defende uma concepção flexível de significado, como a Semântica Cognitiva, nos permita asseverar que vários modos de organização das acepções dos itens seriam possíveis, por outro, contudo, a natureza "bem-delimitada" de um dicionário traz a necessidade de que sejam estipuladas uma estruturação e uma ordenação baseadas em critérios bastante rígidos. Contudo, para fazer propostas com base na noção de polissemia da Semântica Cognitiva, devemos levar em consideração que ainda existem diversos pontos para os quais não há consenso na própria teoria. Não há, por exemplo, consenso a respeito do que seria o "significado básico" ou "prototípico" de um agrupamento, tampouco existe um modelo semânticocognitivo que permita descrever a estrutura semasiológica dos itens lexicais de forma integral. ${ }^{20}$

Partindo da característica prototípica (2), apresentada no Quadro 12, e da necessidade de representação distinta dos quatro dados que surgem dessa

20 É necessário que fique claro que, em nenhum momento, buscamos uma representação para os fenômenos que caracterizamos (no significado semântico-cognitivo do termo), ou seja, uma realidade cognitiva. Tal tentativa seria ingênua e, de forma alguma, caberia neste trabalho. Nosso objetivo é aplicar noções semântico-cognitivas para auxiliar o trabalho lexicográfico. 
concepção no âmbito semasiológico (os efeitos de saliência entre os significados, as relações não hierárquicas entre os significados, as relações hierárquicas entre os significados e a dificuldade no estabelecimento dos limites da polissemia), buscamos delimitar de que forma poderíamos representar essas especificidades no dicionário para a organização do verbete:

1) Determinação do significado central: efeitos de saliência entre os significados

No arcabouço da Semântica Cognitiva, alguns autores atribuem o status de "significado mais básico" ao significado do item com maior frequência de uso. Outros medem esse aspecto a partir de testes experimentais e alguns utilizam como critério a introspecção (GILQUIN, 2008). Contudo, não consideramos a frequência nem a utilização de experimentos como métodos apropriados para determinar a prototipicidade de um significado para a estrutura lexical no âmbito lexicográfico (o primeiro vai contra a ideia de significados agrupados e com sobreposições e o segundo não teria como ser efetivamente empregado para a estruturação de um dicionário, como demonstramos nas análises).

Partimos da noção de que um significado mais básico seria um significado gerador de outros significados mais periféricos. Assim, ele constituiria o centro prototípico que daria homogeneidade entre os significados do item. Esse conceito, ao ser levado ao âmbito lexicográfico, parece auxiliar o consulente no que diz respeito à estruturação da informação (indo do mais geral ao mais específico, do mais concreto ao mais abstrato) e seria um tipo de estruturação diretamente ligada à noção de corporificação. Isso porque se entende que conceitos mais concretos e diretamente relacionados ao funcionamento do corpo humano são utilizados no entendimento de noções mais abstratas, de modo que a apresentação da estrutura semasiológica do item lexical a partir de um significado mais básico auxiliaria nesse entendimento.

Nesse viés, na tentativa de estabelecer critérios que levassem à caracterização do significado mais básico, e que minimizassem os aspectos subjetivos dessa asserção, partimos dos postulados de que um significado mais básico seria (PRAGGLEJAZ GROUP, 2007):

- mais concreto (o que ele evoca é mais fácil de imaginar, ver, ouvir, sentir, cheirar e sentir o gosto);

- relacionado à ação corpórea;

- mais preciso (em oposição a vago);

- historicamente mais antigo;

- não são necessariamente os significados mais frequentes do item lexical. 
Considerando que tais critérios foram originalmente desenvolvidos para delimitar se um significado é básico em comparação a um que seja metafórico, de modo a delimitar o significado básico dentre significados supostamente não metafóricos, adicionamos as seguintes características a essa lista:

- o significado mais básico possui mais atributos em comum quando todos os significados são comparados (advindo da noção original de protótipo referencial: normalmente é o que possui mais características que definem a categoria);

- o significado mais básico, por geralmente dar origem aos outros, é o que apresenta menos especificidade semântica (é mais genérico). Mesmo que esse critério esteja em aparente contradição com o terceiro critério apresentado acima ("mais preciso"), entendemos que no caso de significados que apresentam relação hierárquica ele se aplica. Desse modo, quando tratarmos de relações não hierárquicas optaremos pelo critério de que um significado mais básico é mais preciso, enquanto que quando estivermos diante de uma relação hierárquica julgaremos que o significado básico é o com menos especificidade.

Como não há necessariamente "um único" significado prototípico para um item lexical, entendemos que cada um deles deve ser definido conforme o domínio ou frame em questão. É necessário, então, que haja o seguinte passo: delimitar a qual domínio ou frame pertencem os significados. Caso seja necessária uma definição em um frame mais específico, o significado não é central.

2) Relações hierárquicas entre os significados

Serão representadas por sequências numéricas simples (por exemplo, 1.1 para um significado que constitua uma especialização de 1) ou por meio de uma representação por esquema, quando toda estruturação do item se der por hierarquia. Quando houver uma estruturação por esquema, será apresentada uma definição no estilo catch-all definition no início do verbete.

3) Relações não hierárquicas entre os significados

Esses tipos de relações semânticas serão representadas de forma distinta das relações hierárquicas e, sempre que possível, estarão ligadas a um significado mais básico. Sua representação será por letras minúsculas. Dessa forma, os elementos gráficos responsáveis pela sequência do verbete servirão também para explicitar a forma como os significados estão relacionados entre si.

4) Dificuldade no estabelecimento dos limites da polissemia 
Para comportar os casos nos quais a distinção entre polissemia e vagueza é problemática, serão utilizadas catch-all definitions.

5) Representação da sobreposição semântica e das semelhanças de família

Partiremos de uma representação gráfica dos significados para delimitar qual a ordem de apresentação dos agrupamentos e, para relacionar os diferentes grupos de significados entre si, utilizaremos recursos medioestruturais, com remissões a significados relacionados.

Abaixo, descrevemos de que forma percebemos a organização da categoria lexical band e, ao final, propomos um verbete no qual a teoria semântico-cognitiva, a partir das delimitações acima, tenha sido empregada para a organização dessas informações.

Em primeiro lugar, pelo fato de considerarmos esse um caso de homonímia, com diferenças semânticas bastante evidentes, a primeira divisão que propomos no verbete é a construção de um bloco relativo a pessoas e outro a coisas (que está em consonância com as diferentes origens etimológicas). Esses blocos são separados por numerais romanos, para indicar grupos semânticos contrastantes, contudo, por ser um caso de homonímia, não temos um critério para estabelecer qual bloco será apresentado antes. Temos, desse modo, os seguintes grandes blocos que abrangem os significados apresentados:

I GROUP OF PEOPLE: "bando" e "músicos";

II STRIP: "faixa/amarra", "faixa/aro", "faixa/parte de uma vestimenta" , "listra", "faixa de sintonização" e "faixa de escala".

A partir disso, devemos determinar quais significados serão os núcleos de cada um dos blocos. Considerando o primeiro bloco, relativo a pessoas, pelos primeiros três critérios que estabelecemos, "mais concreto", "relacionado à ação corpórea" e "mais preciso", não conseguimos definir nenhum dos dois significados como o mais básico. Quanto ao fato de qual deles ser historicamente mais antigo, como apresentamos acima, "grupo de pessoas" foi a primeira acepção desse item, que é mais próxima do significado "bando".

Para delimitar os atributos compartilhados, apresentamos o seguinte quadro dos atributos de cada um dos dois significados: 


\section{Quadro 13 - Atributos dos significados "bando" e "músicos" de band}

\begin{tabular}{|l|l|}
\hline Significados & Atributos \\
\hline "bando" & + pessoas \\
& + reunidas em um grupo \\
& + propósito específico \\
\hline \multirow{2}{*}{ "músicos" } & + pessoas \\
& + reunidas em um grupo \\
& + propósito específico \\
& + tocar música \\
\hline
\end{tabular}

Fonte: Oliveira (2010a, p.165).

O significado "bando" é o que possui menos especificidade dentre os dois significados (podendo ser considerado o esquema desse primeiro bloco). Dessa forma, entendemos que o significado "bando" apresenta uma relação hierárquica com o significado "músicos", que, por sua vez, é uma especialização desse esquema. Além disso, o primeiro significado pode ser definido com relação ao frame mais genérico PESSOAS, enquanto o segundo, além de PESSOAS, necessita de um frame mais específico, como TRABALHO ou LAZER, para sua definição.

Consideramos, assim, para esse primeiro bloco, o significado "bando" como mais básico que "músicos", e, por isso, ele será o primeiro a figurar no verbete. Por manterem uma relação hierárquica, o primeiro significado recebe o número 1 e o segundo 1.1 .

Quanto ao segundo bloco, percebemos que quatro desses significados são mais concretos: "faixa/amarra", "faixa/aro", "faixa/parte de uma vestimenta" e "listra". Dos três primeiros, "faixa/amarra" é o significado historicamente mais antigo desse bloco e é o que possui mais extensões (como os próprios significados "faixa/aro" e "faixa/parte de uma vestimenta"). Definimos, assim, que ele será o primeiro significado a ser apresentado no segundo bloco. Quanto às relações semânticas, os significados "faixa/amarra" e "listra" são independentes e serão apresentados no verbete de forma individual, o primeiro na acepção $\mathbf{2}$ e o segundo na 3. Consideramos que o significado "faixa/amarra" deve figurar no verbete antes de "listra", pois tem mais extensões e sua relação com outros significados é mais evidente. ${ }^{21}$

Quanto à ordem dos outros significados, julgamos que "faixa/aro" deve figurar antes de "faixa/parte de uma vestimenta", pois pode ser definido a partir

21 Contudo, não desconsideramos a possível relação entre todos eles, de modo que uma separação com "faixa/ amarra" servindo como núcleo de extensão dos outros significados não pode ser considerada não problemática. 
do mesmo frame do núcleo desse bloco, UTENSÍLIO. Já o segundo recebe uma caracterização em um frame mais específico, de VESTUÁRIO.

Os outros dois significados, "faixa de sintonização" e "faixa de escala" são extensões figuradas, com bastante relação entre si, pois designam (i) extensão de inclusão de um espectro eletromagnético e (ii) extensão de inclusão de elementos, respectivamente. Assim, o atributo [+ para unir elementos] é compartilhado com o significado "faixa/amarra". Desse modo, esses significados seriam os últimos a serem apresentados para o significado "faixa", por constituírem relações não hierárquicas, recebendo as letras $\mathbf{a} \in \mathbf{b}$, que caracterizam extensões.

O verbete que criamos fica da seguinte forma:

\title{
Figura 1 - Proposta de verbete para o item lexical band
}

\author{
band $n .[\mathrm{C}]$ \\ I GROUP OF PEOPLE: 1 a group of people that get together for a \\ particular reason $\mathbf{1 . 1}$ a group of musicians that play a particular kind of \\ music together \\ II STRIP \\ MATERIAL $\mathbf{2}$ a narrow piece of sth that is put around things to hold \\ them together $\mathbf{2 . 1}$ a ring $\mathbf{2 . 2}$ a piece of cloth which forms part of a piece \\ of clothing \\ RANGE $\mathbf{2 . a}$ a range of values to measure sth $\mathbf{2 . b}$ a range of radio waves \\ CONTRAST 3 a strip of sth that contrasts with what is around
}

Fonte: Oliveira (2010a, p.166).

\section{Considerações finais}

Em nossas análises, percebemos que, quanto às soluções empregadas, não há um padrão nos dicionários analisados. Esse fato destaca (i) a dificuldade inerente em lidar com a polissemia e a homonímia nos dicionários; (ii) a falta de sistematicidade na aplicação de um tipo de metodologia por parte das obras e (iii) a possibilidade de que diferentes tipos de estruturação funcionem para a organização dos dicionários.

Quanto à organização das acepções, percebemos que a frequência, tanto por questões anteriores a sua aplicação quanto por problemas exclusivos a esse critério, não parece ser objetiva e estatisticamente aplicável, de forma que novos métodos de organização interna do verbete devam ser propostos e fundamentados teoricamente, principalmente com base em teorias semânticas. 
Desse modo, o desenvolvimento de um modelo mais amplo para a estruturação dos verbetes de learner's dictionaries fundamentado nas concepções semântico-cognitivas de estrutura semasiológica parece ser algo promissor. Porém, faz-se necessário que haja uma validação de tal modelo com o uso de experimentos empíricos, com a comparação entre esse e os outros tipos de verbetes.

Ainda assim, é evidente a falta de uma metodologia mais objetiva de trabalho semântico-lexical por parte do arcabouço cognitivo. Contudo, percebe-se que, mesmo com falta de formalização, tal modelo possui um grande poder explanatório e descritivo, que pode fornecer subsídios bastante úteis ao trabalho lexicográfico. Finalmente, no próprio modelo que criamos, ainda há a necessidade de que sejam ampliadas as possibilidades de representação, por exemplo, das sobreposições semânticas e das semelhanças de família, como quanto ao uso de remissões e de outros recursos medioestruturais.

OLIVEIRA, A. F. S. de; MIRANDA, F. B.; SIQUEIRA, M. Polysemy and homonymy treatment in learner's dictionaries: Cognitive Semantics' insights for the provision of meaning. Alfa, São Paulo, v.57, n.1, p.163-197, 2013.

- ABSTRACT:In lexicographic research, many issues are raised when considering the polysemy and homonymy phenomena. In this paper, two of them are analyzed: (i) the use of a polysemous or homonymic solution for structuring entries; and (ii) the criteria adopted for the provision of meaning within entries. To do so, analyses of lexical items found in four main dictionaries known as learner's dictionary (CALD, 2008; COBUILD, 2006; LDCE, 2009; and OALD, 2005) are presented. We show that solutions applied by dictionaries vary - both among and within a single dictionary - when dealing with the same phenomenon. Additionally, the criterion employed for the provision of meaning - frequency - presents problems, due to issues prior to its application and related to it. Thus, we tried to apply the cognitive semantics' conception of polysemy to design the first steps of a model that could drive the provision of meaning within entries in learner's dictionaries. A suggested entry for the lexical item band is presented. Lastly, some issues our model could efficiently deal with are evaluated and those which remain without solution are discussed.

- KEYWORDS: Lexicography. Polysemy. Cognitive semantics. Learner's dictionaries. Provision of meaning. Polysemous solution. Homonymic solution.

\section{REFERÊNCIAS}

COCK, S. de; GRANGER, S. High frequency words: the bête noire of lexicographers and learners alike. In: EURALEX INTERNATIONAL CONGRESS, 11., 2004, Lorient. Anais... Lorient: Université de Bretagne-Sud, 2004. p.233-243.

CRYSTAL, D. The cambridge encyclopedia of language. Cambridge: CUP, 1997. 
CUYCKENS, H.; ZAWADA, B. Introduction. In: . Polysemy in cognitive linguistics: selected papers from the International Cognitive Linguistics Conference. Amsterdam: John Benjamins, 2001. p.IX-XXVII.

GEERAERTS, D. Theories of lexical semantics. Oxford: OUP, 2010.

. Lexicography. In: GEERAERSTS, D.; CUYCKENS, H. The oxford handbook of cognitive linguistics. New York: OUP, 2007. p.1161-1174.

Prospects and problems of prototype theory. In: GEERAERTS, D. (Org.). Cognitive linguistics: basic readings. Berlin: Mouton de Gruyter, 2006a. p.141-165.

. The lexicographical treatment of prototypical polysemy. In: GEERAERTS, D. Words and other wonders. Berlin: Mouton de Gruyter, 2006b. p.327-344.

The definitional practice of dictionaries and the cognitive semantic conception of polysemy. Lexicographica, Tübingen, v.17, p.6-21, 2001.

Diachronic prototype semantics: a contribution to historical lexicology. Oxford: Claredon Press, 1997.

. Representational formats in cognitive semantics. Folia linguística, Berlim, v.29, n.1, p.21-41, 1995.

GILQUIN, G. Taking a new look at lexical networks. Lexis, Lyon, v.1, p.23-39, 2008.

HAUSMANN, F. J.; WIEGAND, H. E. Theory of monolingual lexicography I: components and structures of dictionaries. In: HAUSMANN, F. J. et al. Wörterbucher, Dictionaries, Dictionnaires: ein internationales handbuch zur lexikographie. Berlin:Walter de Gruyter, 1989. p.328-360.

LEW, R. Towards variable function-dependent sense ordering in future dictionaries. In: BERGENHOLTZ, H.; NIELSEN, S.; TARP, S. (Org.). Lexicography at a crossroad. Bern: Peter Lang, 2009. p.1-18. Disponível em: <http://www.staff.amu.edu. pl/ rlew/pub/Lew_Towards_variable_function-dependent_sense_ordering_in_ future_dictionaries.pdf>. Acesso em: 18 mar. 2010.

OLIVEIRA, A. F. S. Subsídios da semântica cognitiva para a disposição das acepções nos learner's dictionaries. 2010. 231f. Dissertação (Mestrado em Letras) Instituto de Letras, Universidade Federal do Rio Grande do Sul, Porto Alegre, 2010a.

Taxonomia de dicionários monolíngues de inglês para falantes nãonativos. Signo, Santa Cruz do Sul, v.35, n.59, p.224-241, jul.-dez. 2010b. Disponível em: <http://online.unisc.br/seer/index.php/signo/article/viewFile/1429/1307> . Acesso em: 18 jan. 2011.

Questões acerca da adoção da frequência como critério de ordenação das acepções em learner's dictionaries. In: SEMANA DE LETRAS DA PUC-RS, 10., 2010, Porto Alegre. Anais... Porto Alegre: PUC-RS, 2010c. p.1-27. 
PRAGGLEJAZ GROUP. MIP: a method for identifying metaphorically used words in discourse. Metaphor and symbol, Londres, v.22, n.1, p.1-39, 2007.

RAVIN, Y.; LEACOCK, C. Polysemy: an overview. In: Polysemy. theoretical and computational approaches. Oxford: OUP, 2000. p.1-29.

RIEMER, N. Introducing semantics. Cambridge: CUP, 2010.

ROSCH, E. Principles of categorization. In: MARGOLIS, E.; LAURENCE, S. (Org.). Concepts: core readings. Cambridge: MIT Press, 1999. p.189-206.

SARDINHA, T. B. Linguística de corpus. São Paulo: Manole, 2004.

TAYLOR, J. Linguistic categorization. Oxford: Oxford University Press, 2003a. . Polysemy's paradoxes. Language sciences, Oxford, v.25, p.637-655, 2003b.

WERNER, R. La definición lexicográfica. In: HAENSCH, G. et al. La lexicografia: de la lexicografía teórica a la lexicografia práctica. Madrid: Gredos, 1982. p.259-328.

\section{REFERÊNCIAS LEXICOGRÁFICAS}

[CALD]. Cambridge Advanced Learner's Dictionary. Cambridge: Cambridge University Press, 2008.

[COBUILD]. Collins COBUILD Advanced Learner's Dictionary. Glasgow: Harper Collins Publishers, 2006.

[LDCE]. Longman Dictionary of Contemporary English. Essex: Pearson Education Limited, 2009.

[OALD]. HORNBY, A. S. (Ed.). Oxford advanced learner's dictionary. Oxford:

Oxford University Press, 2005.

[OALD]. HORNBY, A. S. (Ed.). Oxford Advanced Learner's Dictionary. Oxford: Oxford University Press, 2010.

[OED]. The Oxford English Dictionary. Oxford: Clarendon Press, 1933.

Recebido em 30 de setembro de 2011.

Aprovado em 24 de novembro de 2012. 
